\title{
The In Vivo Turnover of Individual Cholesterol Esters in Human Plasma Lipoproteins*
}

\author{
DeWitt S. Goodman † \\ (From the Department of Medicine, College of Physicians \& Surgeons, Columbia University, \\ New York, N.Y.)
}

It has long been known that plasma cholesterol consists largely of a mixture of several different fatty acid esters of cholesterol. This was first indicated in 1896, when Hürthle isolated cholesteryl palmitate, oleate, and stearate from an alcoholic extract of serum (1). Subsequent early studies on the ratio of free to ester cholesterol in plasma demonstrated that most of the plasma cholesterol normally exists in ester form (2). More recent studies, using gas-liquid chromatography for the analysis of the cholesterol ester fatty acids, have defined the composition of the plasma cholesterol esters in a variety of species (3-8).

In addition, plasma cholesterol normally is distributed among several different plasma lipoprotein fractions. Most of the plasma cholesterol of man is typically present in the low density, beta-lipoprotein fraction, with smaller amounts present in the high density and the very low density lipoproteins (9-12). These lipoproteins show small but consistent differences in their ratio of free to ester cholesterol $(11,13)$. Recent analyses of the cholesterol ester composition of each human plasma lipoprotein have demonstrated strong similarities in the cholesterol ester composition of the different lipoproteins (13). Small but statistically significant differences do, however, exist between the different lipoproteins. Larger differences between lipoprotein cholesterol ester patterns have been reported by Lindgren and Nichols (14).

Previous studies on the turnover of cholesterol in human plasma have treated plasma cholesterol ester as a single homogeneous entity (15-17). Since plasma cholesterol ester exists as a mixture

* Submitted for publication April 2, 1964; accepted July 2, 1964.

Supported by research grants AM-05986 and HE-05741 from the National Institutes of Health.

$\dagger$ Recipient of Career Scientist Award of the Health Research Council of the City of New York under contract I-399. of different esters distributed among several different lipoproteins, however, multiple possibilities exist for the heterogeneous metabolism of plasma cholesterol esters. Thus, the turnover rates of different cholesterol esters, or of the same or different esters within different lipoproteins, may not be the same. Recent studies on the turnover of individual cholesterol esters in rat plasma have, in fact, demonstrated substantial differences in the turnover rates of the different esters $(18,19)$.

The present study was undertaken to examine the turnover of each different cholesterol ester within each of the three major plasma lipoprotein fractions in man. A preliminary report of some of these results has been published (19).

\section{Methods}

Forty-four microcuries of $\mathrm{DL}-2-\mathrm{C}^{14}$-mevalonic acid, in solution in isotonic saline, was injected intravenously into each of two fasting normal men. The $\mathrm{C}^{14}$-mevalonic acid $^{1}$ was prepared for injection as described earlier (18). The subjects, a 39-year-old Negro (subject WB) and an 18-year-old Caucasian (subject $\mathrm{EH}$ ), ate their usual diets except for a slight reduction in fat intake for one week preceding, and during, the period of the study. Serial blood samples were collected in syringes moistened with a solution of heparin, and plasma samples were collected and processed as described in detail elsewhere (13). In brief, small samples of plasma were extracted immediately, and larger volumes of plasma were used for the serial separation of lipoproteins as discussed by Havel, Eder, and Bragdon (10). Three lipoprotein fractions were collected from each large sample by ultracentrifugation at densities (before centrifugation) of 1.019, 1.063, and 1.21. The lipoprotein and whole plasma samples were extracted with $\mathrm{CHCl}_{3}: \mathrm{MeOH}, 2: 1$ (vol/vol), and the total lipid so obtained was separated into hydrocarbon, cholesterol ester, free cholesterol + triglyceride, and phospholipid fractions by silicic acid column chromatography as previously described (13). The separations were checked repeatedly to ensure a quantitative recovery of cholesterol esters uncontaminated by triglycerides in the second column fraction. Portions of each

1 New England Nuclear Corp., Boston, Mass. 
cholesterol ester and free cholesterol fraction were analyzed for cholesterol mass by the method of Sperry and Webb (20). Duplicate analyses were carried out on each sample; the results of these analyses differed by less than $5 \%$ in every case. Other portions of the cholesterol ester and free cholesterol fractions were assayed for $\mathrm{C}^{14}$ with a Packard liquid scintillation spectrometer, using $0.5 \%$ diphenyloxazole in toluene as solvent. The counting efficiency in this system was $55 \%$. The specific radioactivity of the free cholesterol, and the average specific radioactivity of the esterified cholesterol in each whole cholesterol ester fraction, were then calculated from these data.

The composition of each cholesterol ester fraction was determined by gas-liquid chromatography (GLC) of the cholesterol ester fatty acids as their methyl esters, as detailed earlier (13). The GLC distributions were corrected for the different molecular weights of the different fatty acid methyl esters, and the distribution of cholesterol esters was tabulated in molar terms for each sample. This is equivalent to a tabulation in terms of the distribution of cholesterol mass among the different esters. The complete GLC data on the fatty acid composition of each lipid class in whole plasma and in each plasma lipoprotein for the samples that comprised the present study have been presented elsewhere (13). Both subjects showed only extremely small variation from sample to sample in the concentration and composition of each lipid class in each lipoprotein.

The distribution of radioactivity among the different cholesterol esters in each sample was determined by thin layer chromatography (TLC) on silica gel G impregnated with $\mathrm{AgNO}_{3}$, using benzene-hexane, 1:1 (vol/vol), as ascending solvent, and as previously described in detail (18). This method separates cholesterol esters differing in the number of double bonds in the fatty acid moiety. TLC resolved each sample into four widely separated zones, comprising the saturated cholesterol esters (mainly cholesteryl palmitate, $R_{\mathbf{f}} \sim 0.8$ ), the monounsaturated esters (mainly cholesteryl oleate, $R_{\mathbf{f}} \sim 0.65$ ), the diunsaturated esters (cholesteryl linoleate, $R_{\mathrm{f}} \sim 0.4$ ), and the tetraunsaturated esters (cholesteryl arachidonate, $\left.R_{\mathbf{f}} \sim 0.1\right)$. Each zone was separately scraped on to a filter funnel, eluted with $15 \mathrm{ml} \mathrm{CHCl}$, and assayed for $\mathrm{C}^{14}$. Further elution with hot benzene: ethyl ether, $1: 1$, was carried out to recover completely cholesteryl arachidonate from the $\Delta 4$ zone; the other more saturated esters were satisfactorily eluted with $\mathrm{CHCl}_{3}$ alone.

The validity of this TLC method for the determination of the distribution of cholesterol ester radioactivity has been verified by the analysis of various standard mixtures of pure labeled cholesterol esters (18). Duplicate TLC analyses were carried out on each cholesterol ester sample in the present study. The values for the percentage of distribution of radioactivity in the saturated and mono- and diunsaturated zones agreed within $10 \%$ (usually within 5\%) in almost every pair of analyses. In the very few instances where differences greater than $10 \%$ of the value were observed, one or more additional analyses were carried out. The values for the percentage of total radioactivity in the $\Delta 4$ zones agreed within $20 \%$ of each other on duplicate analysis. This greater relative error in the $\Delta 4$ values largely derived from the relatively small amounts of cholesteryl arachidonate present in the samples. Only the average values for the duplicate analyses have been tabulated in the results that follow.

To compare the distribution of cholesterol ester mass, as determined by GLC, with the $\mathrm{C}^{14}$ distribution as determined by TLC, the saturated and monounsaturated ester mass values were summed for each sample, and the distribution of esterified cholesterol mass was expressed in terms of saturated, $\Delta 1, \Delta 2$, and $\Delta 4$ fractions. Almost identical values were obtained, from sample to sample, for the mass distributions for a given plasma lipoprotein (or for whole plasma). This is indicated by the extremely small standard errors tabulated with the GLC data in earlier work (13). Since the small variations from sample to sample were probably more technical than biological in origin, the values for the various samples were averaged, and only the average values were used as representing the distribution of esterified cholesterol mass in all samples of a given lipoprotein. This procedure thus minimized any small variation from sample to sample that might have been derived from small technical errors in the GLC analyses.

The specific radioactivity of each cholesterol ester fraction in each sample was calculated from the preceding data by multiplying the average specific radioactivity of the whole ester fraction by the ratio of the percentage of total $\mathrm{C}^{14}$ to the percentage of total mass.

\section{Results}

The values of the specific radioactivity of free and esterified cholesterol in the whole plasma samples of each subject, at various time intervals after the injection of DL-2-C $\mathrm{C}^{\mathbf{1 4}}$-mevalonate, are listed in Table I. Labeled free cholesterol rapidly appeared in the plasma, with the maximal specific radioactivity of free cholesterol occurring at approximately 3 hours in both subjects. The time and levels of the peak specific radioactivity of plasma free cholesterol seen here are comparable to those observed by Gidez and Eder in a patient given intravenous $\mathrm{C}^{14}$-mevalonate (17). The peak specific radioactivity for plasma ester cholesterol occurred at approximately 48 hours in both subjects. Equilibration between the free and ester cholesterol occurred more rapidly in subject $\mathrm{EH}$ than in subject WB. Thus, after 24 hours this equilibration was $76 \%$ complete (ester/free $\mathrm{SA}$ ratio, 0.76) in subject $\mathrm{EH}$ but only $50 \%$ complete in WB. After 48 hours equilibration was 
TABLE I

Cholesterol specific radioactivity in whole plasma after intravenous 2-C ${ }^{14}$-mevalonate

\begin{tabular}{|c|c|c|c|c|c|c|c|}
\hline \multirow[b]{3}{*}{ Time } & \multicolumn{3}{|c|}{ Subject WB } & \multicolumn{4}{|c|}{ Subject EH } \\
\hline & \multicolumn{2}{|c|}{$\begin{array}{l}\text { Cholesterol specific } \\
\text { radioactivity }\end{array}$} & \multirow{2}{*}{$\underset{\substack{\text { ratio } \\
\text { Ester/Free }}}{ }$} & \multirow[b]{2}{*}{ Time } & \multicolumn{2}{|c|}{$\begin{array}{l}\text { Cholesterol specific } \\
\text { radioactivity }\end{array}$} & \multirow{2}{*}{ 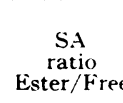 } \\
\hline & Free & Ester & & & Free & Ester & \\
\hline hrs & \multicolumn{2}{|c|}{$\mathrm{counts} / \mathrm{min} / \mathrm{mg}$} & & hrs & \multicolumn{2}{|c|}{ counts $/ \mathrm{min} / \mathrm{mg}$} & \\
\hline 0.93 & 592 & 9.8 & 0.017 & 1.83 & 1,044 & 60 & 0.057 \\
\hline 1.95 & 1,277 & 32 & 0.025 & 2.92 & 1,059 & 92 & 0.086 \\
\hline 3.00 & 1,483 & 60 & 0.040 & 4.83 & 948 & 147 & 0.155 \\
\hline 5.00 & 1,453 & 126 & 0.087 & 7.75 & 733 & 219 & 0.299 \\
\hline 7.25 & 1,144 & 158 & 0.138 & 10.83 & 576 & 235 & 0.408 \\
\hline 12.0 & 886 & 250 & 0.282 & 12.75 & 583 & 250 & 0.43 \\
\hline 15.0 & 771 & 260 & 0.337 & 15.75 & 535 & 291 & 0.54 \\
\hline 24.0 & 626 & 312 & 0.50 & 24.75 & 435 & 331 & 0.76 \\
\hline 48.0 & 492 & 400 & 0.81 & 48.8 & 388 & 375 & 0.97 \\
\hline 72.0 & 457 & 385 & 0.84 & 95.5 & 317 & 342 & 1.08 \\
\hline 120 & 335 & 315 & 0.94 & 169 & 274 & 283 & 1.03 \\
\hline 168 & 307 & 302 & 0.98 & & & & \\
\hline
\end{tabular}

$97 \%$ complete in subject $\mathrm{EH}$ and $81 \%$ in subject WB.

The urine of subject $\mathrm{EH}$ was collected and pooled during the first 48 hours after the mevalonate injection. One $\mathrm{ml}$ of urine was added to 10 $\mathrm{ml}$ of the scintillation mixture described by Bray (21) and was assayed for $\mathrm{C}^{14}$; the observed counts per minute were corrected to the usual efficiency by use of an appropriate internal standard. The pooled urine contained $55 \%$ of the total amount of $\mathrm{C}^{14}$ injected into subject $\mathrm{EH}$. A similar urinary excretion of radioactivity, mainly occurring in the first 12 hours, was also seen by Gidez and Eder in the patient mentioned above (17). Most of this urinary $\mathrm{C}^{14}$ probably consisted of $\mathrm{L}(-)$ mevalonic acid, since it has been shown that only the $\mathrm{D}(+)$ isomer is biologically active (22) and that the $\mathrm{L}(-)$ isomer is primarily excreted in the urine (23). The urinary excretion in excess of $50 \%$ probably reflects the excretion of some of the active isomer during the first hour or two, together with the excretion of some labeled bicarbonate, derived from the $\mathrm{C}^{14} \mathrm{O}_{2}$ released during the course of cholesterol biosynthesis (24).

The specific radioactivity of the free and esterified cholesterol in each plasma lipoprotein, at various time intervals after $\mathrm{C}^{\mathbf{1 4}}$-mevalonate, is listed in Table II. Lipoprotein fractionation was carried out on all the samples from subject $\mathrm{EH}$ but on only four of the plasma samples of subject WB.

TABLE II

Cholesterol specific radioactivity in plasma lipoproteins after intravenous $2-C^{14}$-mevalonate

\begin{tabular}{|c|c|c|c|c|c|c|c|c|c|}
\hline \multirow[b]{3}{*}{ Time } & \multicolumn{3}{|c|}{$\begin{array}{c}\text { Lipoprotein } \\
\rho<1.019\end{array}$} & \multicolumn{3}{|c|}{$\begin{array}{c}\text { Lipoprotein } \\
1.019<\rho<1.063\end{array}$} & \multicolumn{3}{|c|}{$\begin{array}{c}\text { Lipoprotein } \\
1.063<\rho<1.21\end{array}$} \\
\hline & \multicolumn{2}{|c|}{$\begin{array}{l}\text { Cholesterol } \\
\text { specific } \\
\text { radioactivity }\end{array}$} & \multirow{2}{*}{$\begin{array}{c}\text { SA } \\
\text { ratio } \\
\text { Ester/Free }\end{array}$} & \multicolumn{2}{|c|}{$\begin{array}{l}\text { Cholesterol } \\
\text { specific } \\
\text { radioactivity }\end{array}$} & \multirow{2}{*}{$\begin{array}{c}\text { SA } \\
\text { ratio } \\
\text { Fster/Free }\end{array}$} & \multicolumn{2}{|c|}{$\begin{array}{l}\text { Cholesterol } \\
\text { specific } \\
\text { radioactivity }\end{array}$} & \multirow{2}{*}{$\begin{array}{c}\text { SA } \\
\text { ratio } \\
\text { Ester/Free }\end{array}$} \\
\hline & Free & Ester & & Free & Ester & & Free & Ester & \\
\hline hrs & \multicolumn{3}{|c|}{ counts/min/mg } & \multicolumn{3}{|c|}{ counts/min/mg } & \multicolumn{3}{|c|}{ counts $/ \mathrm{min} / \mathrm{mg}$} \\
\hline $\begin{array}{r}\text { Subject WB } \\
3.00 \\
5.00 \\
7.25 \\
24.0\end{array}$ & $\begin{array}{r}1,573 \\
1,376 \\
1,096 \\
624\end{array}$ & $\begin{array}{r}82 \\
111 \\
194 \\
367\end{array}$ & $\begin{array}{l}0.052 \\
0.081 \\
0.18 \\
0.59\end{array}$ & $\begin{array}{r}1,520 \\
1,380 \\
1,184 \\
648\end{array}$ & $\begin{array}{r}29 \\
69 \\
104 \\
297\end{array}$ & $\begin{array}{l}0.019 \\
0.050 \\
0.088 \\
0.46\end{array}$ & $\begin{array}{r}1,580 \\
1,357 \\
1,082 \\
683\end{array}$ & $\begin{array}{l}172 \\
240 \\
276 \\
372\end{array}$ & $\begin{array}{l}0.11 \\
0.18 \\
0.25 \\
0.55\end{array}$ \\
\hline $\begin{array}{r}\text { Subject } \mathrm{EH} \\
1.83 \\
2.92 \\
4.83 \\
7.75 \\
10.83 \\
12.75 \\
15.75 \\
24.75 \\
48.8 \\
98.5 \\
169\end{array}$ & $\begin{array}{r}935 \\
1,142 \\
1,044 \\
766 \\
600 \\
578 \\
520 \\
490 \\
375 \\
339 \\
297\end{array}$ & $\begin{array}{r}31 \\
68 \\
150 \\
264 \\
305 \\
331 \\
331 \\
350 \\
347 \\
344 \\
281\end{array}$ & $\begin{array}{l}0.033 \\
0.060 \\
0.14 \\
0.35 \\
0.51 \\
0.57 \\
0.64 \\
0.71 \\
0.92 \\
1.02 \\
0.95\end{array}$ & $\begin{array}{r}976 \\
1,066 \\
941 \\
766 \\
587 \\
583 \\
552 \\
\mathbf{4 7 9} \\
365 \\
339 \\
251\end{array}$ & $\begin{array}{r}17 \\
44 \\
83 \\
141 \\
170 \\
216 \\
244 \\
303 \\
348 \\
367 \\
281\end{array}$ & $\begin{array}{l}0.018 \\
0.041 \\
0.088 \\
0.18 \\
0.29 \\
0.37 \\
0.44 \\
0.63 \\
0.95 \\
1.08 \\
1.12\end{array}$ & $\begin{array}{r}890 \\
1,051 \\
1,011 \\
788 \\
\mathbf{5 3 0} \\
\mathbf{5 3 1} \\
\mathbf{5 0 1} \\
\mathbf{4 6 5} \\
\mathbf{4 0 3} \\
\mathbf{3 3 4} \\
290\end{array}$ & $\begin{array}{l}131 \\
226 \\
312 \\
369 \\
357 \\
379 \\
388 \\
404 \\
377 \\
326 \\
263\end{array}$ & $\begin{array}{l}0.15 \\
0.22 \\
0.31 \\
0.47 \\
0.67 \\
0.71 \\
0.77 \\
0.87 \\
0.94 \\
0.98 \\
0.91\end{array}$ \\
\hline
\end{tabular}




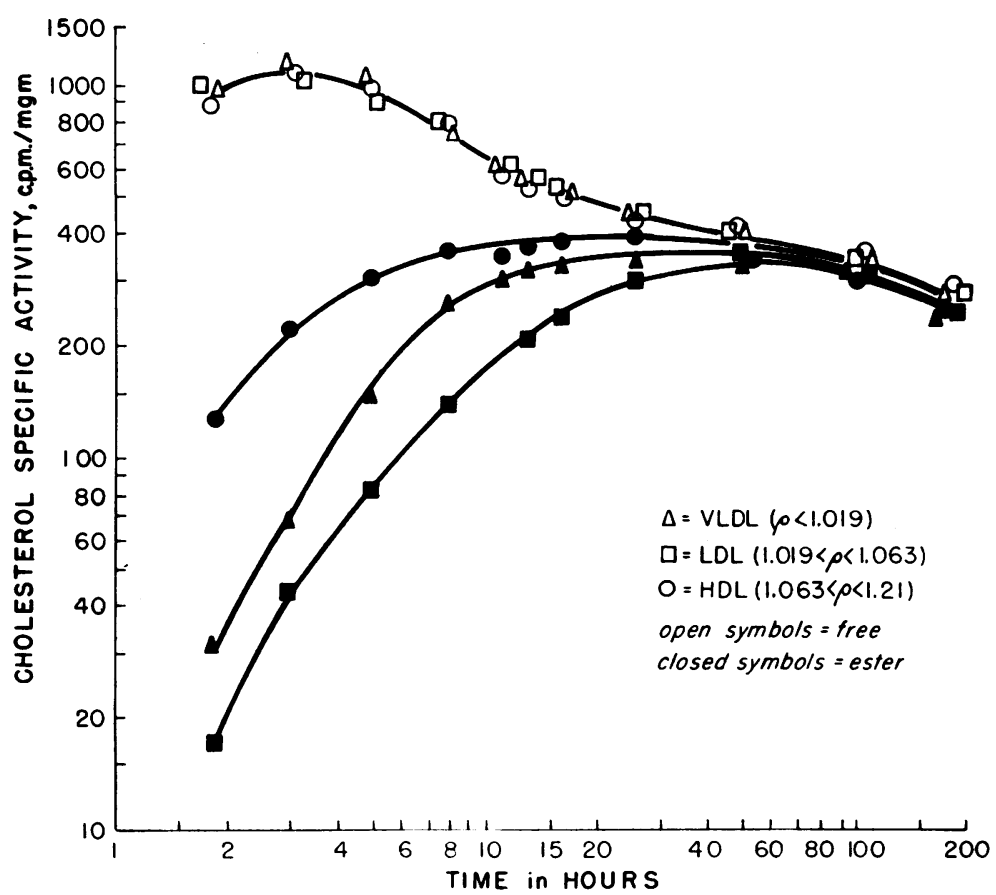

Fig. 1. The SPECIFIC RAdioACtIVITY OF FREE AND ESTERIFIEd CHOLESTEROL IN THE THREE PLASMA LIPOPROTEIN FRACTIONS OF SUBJECT EH AT VARIOUS TIMES AFTER INTRAVENOUS 2-C ${ }^{14}$-MEVALONATE. VLDL = very low density, $\mathrm{LDL}=$ low density, and $\mathrm{HDL}=$ high density lipoproteins.

The free cholesterol specific radioactivities in the three lipoproteins derived from a given plasma sample were nearly identical in all samples. In contrast, marked differences were seen in the specific radioactivities of the esterified cholesterol of the different lipoproteins. In both subjects, radioactivity appeared much more rapidly in the ester cholesterol of the high density (density 1.063 to 1.21 ) lipoprotein than in the ester cholesterol of the other lipoproteins. Radioactivity appeared least rapidly in the low density (density 1.019 to 1.063) lipoprotein ester cholesterol. Most of the data for subject $\mathrm{EH}$ are also shown graphically in a $\log -\log$ plot in Figure 1 . The differences between the three lipoproteins were most marked in the early hours of the study and consisted of specific radioactivity differences of several hundred per cent. After 2 days the differences between the lipoproteins were virtually gone. In the early periods of these studies, the distribution of radioactivity in ester cholesterol in the three lipoproteins differed markedly from the distribution of mass. Both subjects had approximately $25 \%$ of their plasma ester cholesterol mass in the high density lipoproteins and approximately $60 \%$ of the ester cholesterol in the density 1.019 to 1.063 lipoproteins. In both subjects, however, during the first 5 hours more than $50 \%$ of the ester cholesterol $\mathrm{C}^{14}$ was found in the high density lipoprotein. With increasing time the distribution of ester cholesterol $\mathrm{C}^{\mathbf{1 4}}$ approached the mass distribution, as equilibration proceeded among the various cholesterol pools.

The data obtained with the isolated lipoprotein fractions were used to calculate the expected specific radioactivity of the esterified cholesterol in the corresponding samples of whole plasma. The calculated values for whole plasma agreed with the observed values (Table I) within $6 \%$ in every sample. Since the ester cholesterol specific activities in the different lipoproteins differed by several hundred per cent, the close agreement between the calculated and observed values for whole plasma established that no changes or selective losses occurred during the 3 days involved in the lipoprotein fractionations. The specific radioactivity differences observed between the ester cholesterol of the different lipoproteins therefore must have 
TABLE III

Distribution of cholesterol mass among four cholesterol ester fractions in plasma and plasma lipoproteins

\begin{tabular}{lcccc}
\hline \hline & \multicolumn{4}{c}{$\begin{array}{c}\text { Per cent of total esterified } \\
\text { cholesterol* }\end{array}$} \\
\cline { 2 - 5 } & Saturated & $\Delta 1$ & $\Delta 2$ & $\Delta 4$ \\
\hline Subject WB & $\%$ & $\%$ & $\%$ & $\%$ \\
Whole plasma & 15.1 & 26.4 & 50.9 & 7.6 \\
Lipoprotein of density : & 17.5 & 28.9 & 48.5 & 5.1 \\
$\quad<1.019$ & 14.8 & 25.6 & 52.2 & 7.5 \\
1.019-1.063 & 15.0 & 25.5 & 52.6 & 6.9 \\
1.063-1.21 & & & & \\
Subject EH & 14.4 & 23.9 & 56.1 & 5.6 \\
Whole plasma & 12.5 & 26.7 & 55.3 & 5.5 \\
Lipoprotein of density : & 13.3 & 23.1 & 57.7 & 5.9 \\
$\quad<1.019$ & 13.8 & 23.6 & 57.1 & 5.5 \\
1.019-1.063 & & & & \\
$1.063-1.21$ & & &
\end{tabular}

* These are the average values for all the samples of whole plasma or of a given lipoprotein, as determined by gas-liquid chromatography of the cholesterol ester fatty acid methyl esters [see text and (13)].

existed at the time the plasma samples were collected, and hence reflected true in vivo differences. In vitro esterification of free cholesterol (25) probably did not occur during lipoprotein separations because of the low temperatures employed for ultracentrifugation.

The distribution of esterified cholesterol mass among the saturated and mono-, di-, and tetraunsaturated cholesterol esters, for whole plasma and for each plasma lipoprotein in each subject, is shown in Table III. As described under Methods, these data are derived from the complete GLC data given earlier (13). Cholesteryl palmitate and oleate comprised the predominant saturated and monounsaturated esters, respectively. Cholesteryl linoleate and arachidonate were, respectively, the only di- and tetraunsaturated esters.

The data listed in Table III demonstrate for each subject the strong similarities seen in the cholesterol ester compositions of the different lipoproteins. As discussed previously (13), small but statistically significant differences did, however, exist between the different lipoproteins. For both subjects these differences included the occurrence of significantly more oleate in the very low density (density $<1.019$ ) lipoprotein cholesterol esters than in the cholesterol esters of the other lipoproteins. There was also significantly less arachidonate in the very low density lipoprotein cholesterol esters of subject WB compared to his other lipoproteins. None of these differences was sizeable.

Table IV lists the distribution of radioactivity among the four cholesterol ester fractions, as determined by TLC, for each sample of whole plasma or plasma lipoprotein. Table IV also lists the specific radioactivity ratio for each ester fraction relative to the free cholesterol specific radioactivity in the same sample.

Some of the relative specific radioactivity data from Tables II and IV are also shown graphically in Figure 2 for the lipoprotein samples of subject $\mathrm{EH}$. In Figure 2, each vertical column shows the results obtained with one lipoprotein sample. In each column the height of the horizontally striped bar represents the ratio of the average specific radioactivity of the whole cholesterol ester fraction to that of the free cholesterol in the same lipoprotein sample (from Table II). The relative specific radioactivities of the four individual choles-

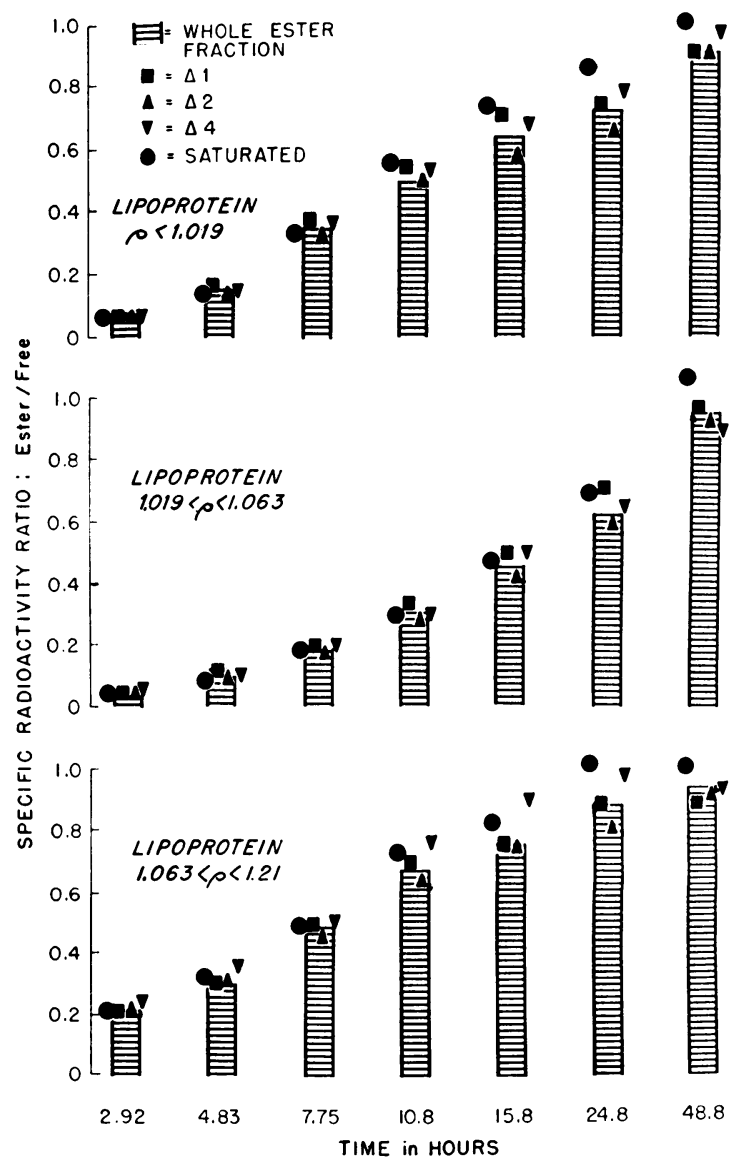

Fig. 2. The Relative SPECific Radioactivity of ChoLESTEROL ESTERS IN THE THREE PLASMA LIPOPROTEIN FRACTIONS OF SUBJECT EH AFTER INTRAVENOUS 2-C 14 -MEVAlONATE. 
TABLE IV

The distribution of cholesterol radioactivity among, and the relative specific radioactivity of, the four cholesterol ester fractions in plasma and plasma lipoproteins

\begin{tabular}{|c|c|c|c|c|c|c|c|c|}
\hline \multirow[b]{2}{*}{ Time } & \multicolumn{4}{|c|}{$\%$ Distribution of cholesterol-C14 } & \multicolumn{4}{|c|}{ Relative SA (free cholesterol $=1.00$ ) } \\
\hline & Saturated & $\Delta 1$ & $\Delta \mathbf{2}$ & $\Delta 4$ & Saturated & $\Delta 1$ & $\Delta 2$ & $\Delta \mathbf{4}$ \\
\hline 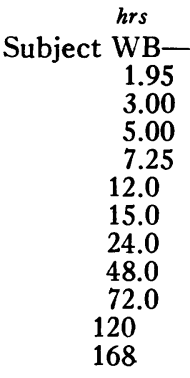 & $\begin{array}{r}\text { lasma } \\
14.7 \\
13.8 \\
15.1 \\
15.5 \\
15.8 \\
15.8 \\
16.2 \\
15.7 \\
15.5 \\
14.8 \\
14.5\end{array}$ & $\begin{array}{l}25.7 \\
28.8 \\
26.7 \\
26.7 \\
26.5 \\
25.9 \\
27.7 \\
29.7 \\
27.0 \\
28.5 \\
28.4\end{array}$ & $\begin{array}{l}51.3 \\
49.2 \\
49.9 \\
49.0 \\
48.4 \\
50.0 \\
48.8 \\
47.0 \\
48.6 \\
49.5 \\
49.6\end{array}$ & $\begin{array}{l}8.3 \\
8.2 \\
8.3 \\
8.7 \\
9.3 \\
8.2 \\
7.4 \\
7.6 \\
8.0 \\
7.2 \\
7.6\end{array}$ & $\begin{array}{l}0.024 \\
0.037 \\
0.087 \\
0.14 \\
0.30 \\
0.35 \\
0.53 \\
0.85 \\
0.86 \\
0.92 \\
0.95\end{array}$ & $\begin{array}{l}0.024 \\
0.044 \\
0.088 \\
0.14 \\
0.28 \\
0.33 \\
0.52 \\
0.91 \\
0.86 \\
1.01 \\
1.06\end{array}$ & $\begin{array}{l}0.025 \\
0.039 \\
0.085 \\
0.13 \\
0.27 \\
0.33 \\
0.48 \\
0.75 \\
0.80 \\
0.91 \\
0.96\end{array}$ & $\begin{array}{l}0.027 \\
0.043 \\
0.09 \\
0.16 \\
0.34 \\
0.36 \\
0.49 \\
0.81 \\
0.89 \\
0.89 \\
0.98\end{array}$ \\
\hline $\begin{array}{r}\text { Subject WB- } \\
3.00 \\
5.00 \\
7.25 \\
24.0\end{array}$ & $\begin{array}{c}\text { tein : } \rho< \\
17.5 \\
16.3 \\
17.1 \\
17.5\end{array}$ & $\begin{array}{l}019 \\
38.1 \\
33.9 \\
30.2 \\
28.4\end{array}$ & $\begin{array}{l}38.3 \\
43.6 \\
46.6 \\
48.9\end{array}$ & $\begin{array}{l}6.1 \\
6.2 \\
6.2 \\
6.3\end{array}$ & $\begin{array}{l}0.052 \\
0.075 \\
0.17 \\
0.59\end{array}$ & $\begin{array}{l}0.069 \\
0.095 \\
0.18 \\
0.58\end{array}$ & $\begin{array}{l}0.041 \\
0.073 \\
0.17 \\
0.59\end{array}$ & $\begin{array}{l}0.06 \\
0.09 \\
0.2 \\
0.7\end{array}$ \\
\hline $\begin{array}{r}\text { Subject WB- } \\
3.00 \\
5.00 \\
7.25 \\
24.0\end{array}$ & $\begin{array}{c}\text { tein : } 1.019 \\
13.6 \\
14.9 \\
14.4 \\
16.1\end{array}$ & $\begin{array}{l}<\rho< \\
26.9 \\
27.1 \\
29.2 \\
28.2\end{array}$ & $\begin{array}{l}50.5 \\
49.6 \\
48.7 \\
47.3\end{array}$ & $\begin{array}{l}9.0 \\
8.3 \\
7.7 \\
8.5\end{array}$ & $\begin{array}{l}0.017 \\
0.051 \\
0.085 \\
0.50\end{array}$ & $\begin{array}{l}0.020 \\
0.053 \\
0.10 \\
0.51\end{array}$ & $\begin{array}{l}0.018 \\
0.048 \\
0.082 \\
0.42\end{array}$ & $\begin{array}{l}0.02 \\
0.05 \\
0.09 \\
0.5\end{array}$ \\
\hline $\begin{array}{r}\text { Subject WB- } \\
3.00 \\
5.00 \\
7.25 \\
24.0\end{array}$ & $\begin{array}{c}\text { tein : } 1.063 \\
15.0 \\
15.6 \\
16.7 \\
15.1\end{array}$ & $\begin{array}{l}<\rho< \\
26.2 \\
26.0 \\
26.3 \\
29.0\end{array}$ & $\begin{array}{l}50.2 \\
50.1 \\
50.5 \\
48.8\end{array}$ & $\begin{array}{l}8.6 \\
8.3 \\
6.6 \\
7.2\end{array}$ & $\begin{array}{l}0.11 \\
0.18 \\
0.28 \\
0.55\end{array}$ & $\begin{array}{l}0.11 \\
0.18 \\
0.26 \\
0.62\end{array}$ & $\begin{array}{l}0.11 \\
0.17 \\
0.25 \\
0.51\end{array}$ & $\begin{array}{l}0.1 \\
0.2 \\
0.2 \\
0.6\end{array}$ \\
\hline $\begin{array}{r}\text { Subject } \mathrm{EH}- \\
4.83 \\
7.75 \\
10.83 \\
15.75 \\
24.75 \\
48.8 \\
169\end{array}$ & $\begin{array}{c}\text { lasma } \\
13.5 \\
14.6 \\
14.1 \\
14.7 \\
15.3 \\
14.1 \\
15.2\end{array}$ & $\begin{array}{l}22.4 \\
25.0 \\
25.9 \\
26.1 \\
26.5 \\
23.4 \\
22.8\end{array}$ & $\begin{array}{l}56.9 \\
55.2 \\
54.5 \\
52.9 \\
52.3 \\
56.0 \\
56.1\end{array}$ & $\begin{array}{l}7.2 \\
5.2 \\
5.5 \\
6.3 \\
5.9 \\
6.5 \\
5.8\end{array}$ & $\begin{array}{l}0.15 \\
0.30 \\
0.39 \\
0.55 \\
0.81 \\
0.95 \\
1.09\end{array}$ & $\begin{array}{l}0.15 \\
0.31 \\
0.44 \\
0.59 \\
0.84 \\
0.95 \\
0.99\end{array}$ & $\begin{array}{l}0.16 \\
0.30 \\
0.40 \\
0.51 \\
0.71 \\
0.96 \\
1.03\end{array}$ & $\begin{array}{l}0.2 \\
0.3 \\
0.4 \\
0.6 \\
0.8 \\
1.1 \\
1.1\end{array}$ \\
\hline $\begin{array}{r}\text { Subject } \mathrm{EH}- \\
2.92 \\
4.83 \\
7.75 \\
10.83 \\
15.75 \\
24.75 \\
48.8 \\
169\end{array}$ & $\begin{array}{c}\text { ein : } \rho<1 \\
11.5 \\
12.5 \\
12.4 \\
13.5 \\
14.5 \\
15.1 \\
13.6 \\
14.0\end{array}$ & $\begin{array}{l}19 \\
27.4 \\
29.4 \\
28.3 \\
28.2 \\
29.2 \\
27.6 \\
26.2 \\
25.7\end{array}$ & $\begin{array}{l}54.9 \\
52.9 \\
53.5 \\
52.6 \\
50.5 \\
51.3 \\
54.4 \\
55.1\end{array}$ & $\begin{array}{l}6.2 \\
5.2 \\
5.8 \\
5.7 \\
5.8 \\
6.0 \\
5.8 \\
5.1\end{array}$ & $\begin{array}{l}0.055 \\
0.14 \\
0.34 \\
0.55 \\
0.74 \\
0.86 \\
1.01 \\
1.06\end{array}$ & $\begin{array}{l}0.062 \\
0.16 \\
0.37 \\
0.54 \\
0.70 \\
0.74 \\
0.91 \\
0.91\end{array}$ & $\begin{array}{l}0.060 \\
0.14 \\
0.33 \\
0.48 \\
0.58 \\
0.66 \\
0.91 \\
0.94\end{array}$ & $\begin{array}{l}0.07 \\
0.14 \\
0.36 \\
0.5 \\
0.7 \\
0.8 \\
1.0 \\
0.9\end{array}$ \\
\hline $\begin{array}{r}\text { Subject } \mathrm{EH}- \\
2.92 \\
4.83 \\
7.75 \\
10.83 \\
15.75 \\
24.75 \\
48.8 \\
169\end{array}$ & $\begin{array}{c}\text { ein : } 1.019 \\
12.6 \\
12.0 \\
12.9 \\
13.1 \\
14.2 \\
14.5 \\
15.0 \\
14.6\end{array}$ & $\begin{array}{l}\rho \rho< \\
23.1 \\
24.2 \\
24.0 \\
25.3 \\
25.6 \\
25.5 \\
23.3 \\
22.9\end{array}$ & $\begin{array}{l}57.9 \\
57.1 \\
56.7 \\
55.8 \\
53.6 \\
54.0 \\
56.2 \\
55.8\end{array}$ & $\begin{array}{l}6.4 \\
6.7 \\
6.4 \\
5.8 \\
6.6 \\
6.0 \\
5.5 \\
6.6\end{array}$ & $\begin{array}{l}0.039 \\
0.080 \\
0.18 \\
0.29 \\
0.47 \\
0.69 \\
1.07 \\
1.23\end{array}$ & $\begin{array}{l}0.041 \\
0.092 \\
0.19 \\
0.32 \\
0.49 \\
0.70 \\
0.96 \\
1.11\end{array}$ & $\begin{array}{l}0.041 \\
0.087 \\
0.18 \\
0.28 \\
0.41 \\
0.59 \\
0.93 \\
1.08\end{array}$ & $\begin{array}{l}0.04 \\
0.10 \\
0.20 \\
0.29 \\
0.49 \\
0.6 \\
0.9 \\
1.2\end{array}$ \\
\hline $\begin{array}{r}\text { Subject } \mathrm{EH}- \\
2.92 \\
4.83 \\
7.75 \\
10.83 \\
15.75 \\
24.75 \\
48.8 \\
169\end{array}$ & $\begin{array}{c}\text { ein : } 1.063 \\
13.6 \\
14.2 \\
14.4 \\
15.0 \\
14.9 \\
16.2 \\
14.9 \\
15.1\end{array}$ & $\begin{array}{l}\rho< \\
22.8 \\
23.2 \\
24.5 \\
24.6 \\
23.1 \\
24.2 \\
22.4 \\
22.7\end{array}$ & $\begin{array}{l}\mathbf{5 7 . 5} \\
56.2 \\
54.6 \\
54.2 \\
55.3 \\
53.3 \\
57.1 \\
56.1\end{array}$ & $\begin{array}{l}6.1 \\
6.4 \\
6.4 \\
6.2 \\
6.7 \\
6.2 \\
5.6 \\
6.1\end{array}$ & $\begin{array}{l}0.21 \\
0.32 \\
0.49 \\
0.73 \\
0.83 \\
1.02 \\
1.01 \\
0.99\end{array}$ & $\begin{array}{l}0.21 \\
0.30 \\
0.49 \\
0.70 \\
0.76 \\
0.89 \\
0.89 \\
0.88\end{array}$ & $\begin{array}{l}0.22 \\
0.30 \\
0.45 \\
0.64 \\
0.75 \\
0.81 \\
0.94 \\
0.89\end{array}$ & $\begin{array}{l}0.24 \\
0.36 \\
0.5 \\
0.7 \\
0.9 \\
1.0 \\
0.95 \\
1.0\end{array}$ \\
\hline
\end{tabular}


terol ester fractions in each sample (from Table IV) are plotted as points in the same vertical column. The potential error in the relative specific radioactivity values for the individual cholesterol esters (Table IV) is probably of the order of $\pm 10 \%$ for the saturated and mono- and diunsaturated esters. The uncertainty in the $\Delta 4$ relative specific activity values is probably $\pm 20 \%$. The lesser reliability of the $\Delta 4$ values in Table IV derives from the small amount of radioactivity found in the $\Delta 4$ zones; a small amount of contamination of radioactivity from the preceding zones would introduce a relatively large error in the $\Delta 4$ value.

In both subjects, for each lipoprotein considered separately and for whole plasma, radioactivity appeared in the different cholesterol esters at a rate proportional to the relative mass of each cholesterol ester. Thus, in each lipoprotein and in whole plasma, the relative rate of appearance of radioactivity was the same for all individual cholesterol esters. This is most clearly indicated by the relative specific radioactivity data of Table IV and Figure 2. At all time intervals the relative specific radioactivities of the different cholesterol esters in each sample were virtually identical. The only exception occurred with the very low density (density $<1.019$ ) lipoprotein of subject $\mathrm{WB}$, which showed relatively more radioactivity in the monounsaturated esters in the earliest two samples analyzed. This difference was not large and was very transient; it was gone by 7.25 hours, although the extent of equilibration of free and ester cholesterol in this lipoprotein was less than $20 \%$ at that time. In contrast, large differences were seen previously in the relative rates of labeling of the different cholesterol esters of rat whole plasma, and these differences extended throughout the period of equilibration of free and ester cholesterol $(18,19)$. In all the other samples of both subjects $\mathrm{WB}$ and $\mathrm{EH}$, the small differences seen in the relative specific radioactivity values for the different cholesterol esters were within the limits of error as discussed above.

\section{Discussion}

The studies reported here demonstrate marked differences in the relative rates of appearance of radioactivity, after intravenous $\mathrm{C}^{\mathbf{1 4}}$-mevalonate, in the cholesterol esters of the various human plasma lipoproteins. These differences probably reflect comparable differences in the turnover rates of the cholesterol esters of the different lipoproteins, since a steady state probably existed in these postabsorptive subjects with unchanging plasma lipid concentrations. Both subjects showed the greatest fractional turnover rate in the high density lipoprotein cholesterol esters and the smallest fractional turnover rate in the low density (density 1.019 to 1.063 ) lipoprotein cholesterol esters. The fractional turnover of the very low density (density < 1.019) lipoprotein cholesterol esters, which comprised only a very small portion of the total plasma cholesterol ester mass, was intermediate in extent.

Similar data on the in vivo turnover of ester cholesterol in different plasma lipoproteins are not available for experimental animals or from other human studies. Kritchevsky, Shapiro, and Werthessen studied the turnover of the serum free and ester cholesterol, and of the total cholesterol of the $\alpha^{-}$and $\beta$-lipoproteins, in a baboon given $\mathrm{C}^{14}$-mevalonate by stomach tube (26). They found that the specific radioactivity-time curves were practically identical for the two lipoproteins. Unfortunately, the blood samples were not large enough to permit separate determinations for free and ester cholesterol in the two lipoprotein fractions. Gidez and Eder stated in an abstract (27) that in a patient given $\mathrm{C}^{14}$-mevalonate the specific activity of the cholesterol esters of the lipoprotein fraction with density 1.019 to 1.063 was lower than that of the cholesterol esters of the other lipoprotein fractions; the details of this work have not been published. Information is available about the relative turnover of cholesterol esters in different rat plasma lipoproteins in vitro from the rat liver perfusion studies of Roheim and his associates (28). During perfusion of livers containing labeled cholesterol from either normal or cholesterol-fed rats, the fastest relative turnover of ester cholesterol occurred in the very low density $(<1.019)$ lipoprotein fraction. This observation was consonant with the results of previous rat liver perfusion studies by these workers, which showed the fastest relative turnover of lipoprotein protein in the very low density fraction (29).

In the present work, the specific radioactivity of the free cholesterol in the different lipoproteins 
was nearly identical in all samples of plasma. This finding was not surprising, since free cholesterol has been shown to undergo rapid and complete in vitro exchange between different lipoproteins $(28,30,31)$. This exchange also occurs between the free cholesterol of plasma and red cells, and plasma and liver, and presumably accounts for the observed rapid appearance of labeled plasma free cholesterol subsequent to the biosynthesis of labeled cholesterol from $\mathrm{C}^{\mathbf{1 4}}$-mevalonate in the liver. A slower exchange has also been demonstrated with plasma phosphatides (32, 33) and with triglycerides (34). The maximal extent of equilibration that could result from in vitro exchange has not been established for these two lipid classes. Although the mechanisms involved in the exchange process have not been defined, the fact of exchange tends to obscure the demonstration of metabolic differences that might exist between different lipoproteins for these lipid classes.

In contrast to free cholesterol, virtually no exchange of ester cholesterol occurs in vitro $(28,31)$. The absence of ester cholesterol exchange was reflected, in the present study, in the very different ester cholesterol specific radioactivities seen in the different lipoproteins. The finding of these differences established the absence of exchange in vivo as well as in vitro and permits the interpretation of specific radioactivity changes in each lipoprotein in terms of relative turnover rates. It has been suggested (28) that since ester cholesterol does not exchange among lipoproteins, study of ester cholesterol turnover in the various lipoproteins may provide information about the metabolism of the entire lipid portion of the various lipoproteins. Although this may be true, the present finding of the highest fractional turnover rate in cholesterol esters of high density lipoproteins should not be applied to other portions of the lipoprotein molecules without further information. Potential discrepancies are suggested by the work of Gitlin and co-workers (35), who observed a slower fractional turnover of $\mathrm{I}^{131}$-labeled protein in high density compared to low density human lipoproteins. In addition, Havel (36) has reported in human subjects the most rapid relative incorporation of circulating free fatty acids into very low density $(<1.006)$ lipoprotein triglycerides. Further work is clearly needed on the me- tabolism of the various moieties comprising each human plasma lipoprotein.

The results presented here also show that all different cholesterol esters were turning over at the same fractional rate within each lipoprotein. Since the turnover rate of the whole cholesterol ester fraction of each lipoprotein differed from that of the other lipoproteins, the fractional turnover rate of each ester within each lipoprotein must have correspondingly differed from the fractional turnover rate of the same ester in the other lipoproteins. For each lipoprotein, however, the entire cholesterol ester mixture behaved as a single homogeneous pool. Since the cholesterol ester compositions of the various lipoproteins were very similar, homogeneous turnover of all cholesterol esters in each lipoprotein was reflected in the finding that all the different cholesterol esters of whole plasma were turning over with the same fractional turnover rate.

Very different results were obtained in a similar study on the turnover of individual cholesterol esters in rat whole plasma $(18,19)$. A much more rapid fractional turnover rate was seen in the monounsaturated compared to the other cholesterol esters in rat plasma. This finding suggests that major variations exist in the metabolism of plasma cholesterol esters in man and the rat. More information is needed on the turnover of different cholesterol esters in each rat plasma lipoprotein.

Portman and Sugano have reported the results of experiments dealing with the metabolism of individual cholesterol esters in monkey whole plasma (37). Six female Cebus monkeys were injected intraperitoneally with $\mathrm{C}^{\mathbf{1 4}}$-mevalonate, and the distribution of cholesterol ester radioactivity among four cholesterol ester groups was determined after 2 hours, 1 day, 3 days, and at intervals thereafter. The distribution of radioactivity in the different cholesterol esters agreed fairly well with the composition of the total cholesterol ester fatty acids as determined by GLC. Of interest is the fact that the plasma cholesterol ester composition observed in these monkeys was similar to that seen in man. These results suggest that the different plasma cholesterol esters of Cebus monkeys are all turning over at the same relative rate, similar to the results obtained in the present study with human subjects. This conclusion should only be considered as tentative, 
however, because the analyses were carried out on only one early sample (at 2 hours) during the period when label was first accumulating in the ester cholesterol fractions. Since the free and ester cholesterol pools of plasma eventually come into isotopic equilibrium, meaningful metabolic conclusions can only be derived from early plasma samples, before such equilibrium has been achieved.

Uncertainty exists as to the mechanisms responsible for the plasma cholesterol ester turnovers seen in the present study. The processes that might be involved in this turnover have been discussed in detail elsewhere (18). One possibility is that turnover depends upon continuing hydrolysis of plasma cholesterol esters, followed by esterification of free cholesterol, within plasma lipoproteins. If this occurs, hydrolysis probably takes place during lipoprotein circulation through the liver and involves liver enzymes, since cholesterol ester hydrolytic enzyme activity has not been found in human plasma (38). Such hydrolytic activity has been found only in dog serum, and not in the serum of a number of other species (38). The characteristics of the rat liver enzymes involved in cholesterol ester hydrolysis have been defined (39), but similar information is not available for other species. Esterification of plasma free cholesterol, on the other hand, might occur either in the liver or in situ in the plasma. Cholesterol esterification in rat liver involves the reaction of free cholesterol with a fatty acylcoenzyme A thiol ester (40). In contrast, cholesterol esterification seen in plasma in vitro has been shown by Glomset (25) to primarily involve a transferase reaction between free cholesterol and the $\beta$ fatty acids of plasma lecithin.

As discussed previously (18), a second possible mechanism involved in the plasma cholesterol ester turnover observed here might be the removal of intact cholesterol esters during their circulation through tissues (including the liver), followed by replacement of the removed esters during circulation through the liver. Finally, there is the possibility that the observed turnover reflected equilibration of the plasma cholesterol esters, by exchange, with a turning-over pool of liver cholesterol esters. It has been pointed out (18) that for such equilibration to occur it would be necessary to postulate the occurrence of some conformational change in the lipoprotein during its circulation through the liver.

More information is needed to assess the relative roles of cholesterol esterification in liver and plasma in the normal formation and turnover of plasma cholesterol esters. The potential importance of the plasma mechanism is suggested by the fact that the initial rate of transesterification observed in vitro (25) is of an order of magnitude similar to the turnover rate of cholesterol esters seen in human whole plasma in vivo. On the other hand, the different turnover rates of cholesterol esters seen here in different plasma lipoproteins conflict with the properties of the plasma transesterification reaction. Thus, after in vitro incubation of human plasma, the increments in ester cholesterol in each lipoprotein were proportional to the original concentration of free cholesterol in each lipoprotein fraction (41). In contrast, in vivo turnover is relatively much more rapid in the high density lipoprotein fraction. More information is needed about the relative participation of different lipoproteins in the in vitro transesterification reaction at short time intervals. It has also been suggested (25) that the operation of the plasma reaction might explain the high proportion of polyunsaturated fatty acids seen in plasma cholesterol esters. For this to be so for man, this reaction would have to display specificity for certain particular tatty acids in the $\beta$-position of lecithin. This conclusion derives from the present finding that the different plasma cholesterol esters were all turning over with the same fractional rate, despite the fact that the composition of the plasma cholesterol esters differed considerably from that of the fatty acids attached to the $\beta$-position of lecithin. Unpublished studies from this laboratory have demonstrated a much higher ratio of arachidonic to linoleic acid in the $\beta$-position of lecithin than in cholesterol esters in human whole plasma and plasma lipoproteins (see also the phospholipid composition data in reference 13). Experiments with rat plasma (25) have suggested that the plasma transesterification reaction does not display specificity for particular fatty acids in the $\beta$-position of lecithin. Comparable experiments have not been carried out with human plasma.

Although the results presented here do not define the mechanisms involved in plasma cholesterol 
ester turnover, they do indicate that the mechanisms responsible for the turnover of cholesterol esters in each lipoprotein apparently operated equally on all the cholesterol esters in a given lipoprotein. Thus, for each human plasma lipoprotein, the entire cholesterol ester mixture behaved as if it were a homogeneous pool. In addition, homogeneous turnover of cholesterol ester mixtures in each lipoprotein, with similar ester compositions in the different lipoproteins, suggests that the same mechanisms were responsible for cholesterol ester turnover in all the lipoproteins, but that these mechanisms operated at different rates for the different lipoproteins.

\section{Summary}

Studies have been conducted of the turnover rates of individual cholesterol esters in whole plasma and in each of three plasma lipoprotein fractions in man. Two normal fasting men were injected intravenously with $2-\mathrm{C}^{14}$-mevalonic acid, and plasma samples were collected at time intervals varying from 1 hour to 7 days. Most of the plasma samples were separated into three lipoprotein fractions by serial ultracentrifugation at densities of $1.019,1.063$, and 1.21. The cholesterol ester and free cholesterol fractions were isolated by silicic acid column chromatography of the total lipid extracts, and the specific radioactivity of the free and esterified cholesterol in each sample was determined. The distribution of cholesterol mass and radioactivity among the several different esters were determined, respectively, by gas-liquid chromatography of the cholesterol ester fatty acid methyl esters and by thin-layer chromatography on silver nitrate impregnated silica gel. The specific radioactivity of each different cholesterol ester (saturated, and mono-, di, and tetraunsaturated esters) was then calculated from these data.

Marked differences were observed in the relative rates of appearance of radioactivity in the cholesterol esters of the various plasma lipoproteins. Both subjects showed the greatest fractional turnover rate in the high density lipoprotein cholesterol esters and the smallest fractional turnover rate in the low density (density 1.019 to 1.063 ) lipoprotein cholesterol esters. Within each lipoprotein, all the different cholesterol es- ters turned over at the same fractional rate. Heterogeneity among plasma cholesterol esters in man therefore exists between the different plasma lipoproteins, rather than between the different esters in a given lipoprotein. The results suggest that the mechanisms responsible for the turnover of plasma cholesterol esters operate equally on all the cholesterol esters in a given lipoprotein, and that the same mechanisms operate, albeit at different rates, in the different lipoproteins.

\section{Acknowledgments}

I wish to express my thanks to Mr. T. Shiratori and Miss C. Goldman for their expert assistance in carrying out this work.

\section{References}

1. Hürthle, K. Uber die Fettsäure-Cholesterin-Ester des Blutserums. Hoppe-Seylers Z. physiol. Chem. 1896, $21,331$.

2. Bloor, W. R., and A. Knudson. Cholesterol and cholesterol esters in human blood. J. biol. Chem. 1917, $29,7$.

3. Swell, L., H. Field, Jr., and C. R. Treadwell. Correlation of arachidonic acid of serum cholesterol esters in different species with susceptibility to atherosclerosis. Proc. Soc. exp. Biol. (N. Y.) 1960, 104, 325.

4. Rehnborg, C. S., A. V. Nichols, and J. K. Ashikawa. Fatty acid composition of mouse lipids and lipoproteins. Proc. Soc. exp. Biol. (N. Y.) 1961, 106, 547.

5. Albers, H. J., and S. Gordon. Comparison of serum cholesterol esters in gerbil and rat. Proc. Soc exp. Biol. (N. Y.) 1962, 109, 860.

6. Leat, W. M. F. Fatty acid composition of the serum lipids of pigs given different amounts of linoleic acid. Biochem. J. 1963, 89, 44.

7. Hallgren, B., S. Stenhagen, A. Svanborg, and L. Svennerholm. Gas chromatographic analysis of the fatty acid composition of the plasma lipids in normal and diabetic subjects. J. clin. Invest. 1960, 39, 1424.

8. Swell, L., H. Field, Jr., and C. R. Treadwell. Relation of age and race to serum cholesterol ester fatty acid composition. Proc. Soc. exp. Biol. (N. Y.) 1960, 105, 129.

9. Oncley, J. L. Lipoproteins of human plasma. Harvey Lect. 1954-55, 50, 71.

10. Havel, R. J., H. A. Eder, and J. H. Bragdon. The distribution and chemical composition of ultracentrifugally separated lipoproteins in human serum. J. clin. Invest. 1955, 34, 1345.

11. Bragdon, J. H., R. J. Havel, and E. Boyle. Human serum lipoproteins. I. Chemical composition of four fractions. J. Lab. clin. Med. 1956, 48, 36. 
12. Lindgren, F. T., A. V. Nichols, and N. K. Freeman. Physical and chemical composition studies on the lipoproteins of fasting and heparinized human sera. 'J. phys. Chem. 1955, 59, 930.

13. Goodman, DeW. S., and T. Shiratori. The fatty acid composition of human plasma lipoprotein fractions. J. Lipid Res. 1964, 5, 307.

14. Lindgren, F. T., and A. V. Nichols. Fatty acid composition of the serum lipoproteins. Ann. N. Y. Acad. Sci. 1961, 94, 55.

15. Rosenfeld, R. S., and L. Hellman. The relation of plasma and biliary cholesterol to bile acid synthesis in man. J. clin. Invest. 1959, 38, 1334.

16. Chobanian, A. V., B. A. Burrows, and W. Hollander. Body cholesterol metabolism in man. II. Measurement of the body cholesterol miscible pool and turnover rate. J. clin. Invest. 1962, 41, 1738.

17. Gidez, L. I., and H. A. Eder. Cholesterol turnover in man in Effects of Drugs on Synthesis and Mobilization of Lipids, E. C. Horning, Ed. New York, Pergamon Press, 1963, p. 67.

18. Goodman, DeW. S., and T. Shiratori. The in vivo turnover of different cholesterol esters in rat liver and plasma. J. Lipid Res., in press.

19. Goodman, DeW. S., and T. Shiratori. The turnover of individual cholesterol esters in human and rat plasma. Biochim. biophys. Acta (Amst.) 1964, 84, 104.

20. Sperry, W. M., and M. Webb. A revision of the Schoenheimer-Sperry method for cholesterol determination. J. biol. Chem. 1950, 187, 97.

21. Bray, G. A. A simple efficient liquid scintillator for counting aqueous solutions in a liquid scintillation counter. Analyt. Biochem. 1960, 1, 279.

22. Wagner, A. F., and K. Folkers. The organic and biological chemistry of mevalonic acid. Endeavour 1960, 20, 177.

23. Cornforth, R. H., K. Fletcher, H. Hellig, and G. Popják. Stereospecificity of enzymic reactions involving mevalonic acid. Nature (Lond.) 1960, $185,923$.

24. Popják, G., and J. W. Cornforth. The biosynthesis of cholesterol. Advanc. Enzymol. 1960, 22, 281.

25. Glomset, J. A. The mechanism of the plasma cholesterol esterification reaction: plasma fatty acid transferase. Biochim. biophys. Acta (Amst.) 1962, 65, 128.

26. Kritchevsky, D., I. L. Shapiro, and N. T. Werthessen. Biosynthesis of cholesterol in the baboon. Biochim. biophys. Acta (Amst.) 1962, 65, 556.
27. Gidez, L. I., and H. A. Eder. Cholesterol metabolism in man (abstract). Biochem. Pharmacol. 1961, 8, 86.

28. Roheim, P. S., D. E. Haft, L. I. Gidez, A. White, and H. A. Eder. Plasma lipoprotein metabolism in perfused rat livers. II. Transfer of free and esterified cholesterol into the plasma. J. clin. Invest. 1963, 42, 1277.

29. Haft, D. E., P. S. Roheim, A. White, and H. A. Eder. Plasma lipoprotein metabolism in perfused rat livers. I. Protein synthesis and entry into the plasma. J. clin. Invest. 1962, 41, 842.

30. Hagerman, J. S., and R. G. Gould. The in vitro interchange of cholesterol between plasma and red cells. Proc. Soc. exp. Biol. (N. Y.) 1951, 78, 329.

31. Goodman, DeW. S. The metabolism of chylomicron cholesterol ester in the rat. J. clin. Invest. 1962, $41,1886$.

32. Kunkel, H. G., and A. G. Bearn. Phospholipid studies of different serum lipoproteins employing $\mathrm{P}^{32}$. Proc. Soc. exp. Biol. (N. Y.) 1954, 86, 887.

33. Eder, H. A. The lipoproteins of human serum. Amer. J. Med. 1957, 23, 269.

34. Havel, R. J., J. M. Felts, and C. M. Van Duyne. Formation and fate of endogenous triglycerides in blood plasma of rabbits. J. Lipid Res. 1962, 3, 297.

35. Gitlin, D., D. G. Cornwell, D. Nakasato, J. L. Oncley, W. L. Hughes, Jr., and C. A. Janeway. Studies on the metabolism of plasma proteins in the nephrotic syndrome. II. The lipoproteins. J. clin. Invest. 1958, 37, 172.

36. Havel, R. J. Conversion of plasma iree fatty acids into triglycerides of plasma lipoprotein fractions in man. Metabolism 1961, 10, 1031.

37. Portman, O. W., and M. Sugano. The hydrolysis and fatty acid exchange of cholesterol esters administered in lipoproteins to Celuus monkeys. Arch. Biochem. 1963, 102, 335.

38. Swell, L., and C. R. Treadwell. Cholesterol esterases. III. Occurrence and characteristics of cholesterol esterase of serum. J. biol. Chem. 1950, 185, 349.

39. Deykin, D., and DeW. S. Goodman. The hydrolysis of long-chain fatty acid esters of cholesterol with rat liver enzymes. J. biol. Chem. 1962, 237, 3649.

40. Goodman, DeW. S., D. Deykin, and T. Shiratori. The formation of cholesterol esters with rat liver enzymes. J. biol. Chem. 1964, 239, 1335.

41. Glomset, J. A. Further studies of the mechanism of the plasma cholesterol esterification reaction. Biochim. biophys. Acta (Amst.) 1963, 70, 389. 